\title{
Preliminary Study of Prostatic Fluid Levels of Zinc Concentration as the Biodosimeter of Males Exposure to Ionizing Radiation
}

\section{Vladimir Zaichick ${ }^{1 *}$ and Sofia Zaichick ${ }^{2}$}

${ }^{1}$ Radionuclide Diagnostics Department, Medical Radiological Research Centre, Obninsk, Russia

${ }^{2}$ Laboratory of Dr. Gabriela Caraveo Piso, Feinberg School of Medicine, Northwestern University, Chicago, USA

*Corresponding Author: Vladimir Zaichick, Radionuclide Diagnostics Department, Medical Radiological Research Centre, Obninsk, Russia.

DOI: $10.31080 /$ ASMS.2020.04.0555
Received: January 17, 2020

Published: February 08, 2020

(C) All rights are reserved by Vladimir

Zaichick and Sofia Zaichick.

\begin{abstract}
Among different bio dosimeters, there is a need in methods that can rapidly and accurately determine individual exposure to ionizing radiation during examination a big cohort of people, particularly men. In present study contents of trace elements in the prostatic fluid were investigated to search for a new biological dosimeter. Prostatic fluid samples were obtained from 15 men aged 38 - 77 years suffering from bladder cancer. All patients were treated with external (distant) gamma-ray therapy. Fractionated tumour irradiation was used with a total dose of $65 \mathrm{~Gy}$. The tumour was daily irradiated with the dose ranged from 6 to $12 \mathrm{~Gy}$. The prostate radiation dose was calculated according to the distribution of isodose levels within patient's body during the simulation of external local gamma-ray irradiation of bladder tumour. Transrectal digital massage was used to obtain expressed prostatic fluid samples before and 2 - 4 times during radiation therapy for the energy dispersive X-ray fluorescent analysis. A day after the first irradiation of the prostate with the average dose $4.6 \mathrm{~Gy}$ to prostate concentration of zinc in the prostatic fluid was about three times lower the metal level before gamma-ray therapy. The dose detection threshold was calculated up to $0.1 \mathrm{~Gy}$. The exponential function was the best for approximation the "dose-effect" dependence of the zinc level in prostatic fluid from the radiation exposure during external gamma-ray therapy of patients with bladder cancer.
\end{abstract}

Keywords: Prostate; Prostatic Fluid; Biomarkers; Trace Elements; Zinc; Biological Dosimetry

\section{Abbreviations}

TE: Trace Element; EPF: Expressed Prostatic Fluid; IR: Ionizing Radiation; EDXRF: Energy Dispersive X-Ray Fluorescent Microanalysis.

\section{Introduction}

The increase usage of radionuclides in medicine, meteorology, agriculture, industry and army as well as the expansion of nuclear power stations is directly associated with the increasing probability of nuclear and radiation emergencies. At present, there is also a great risk of terrorist nuclear attacks. The occupational workers always wear personal radiation dosimeters while at the time of the radiation accident with individuals within the population the exposed persons do not have any dosimeter. Biodosimetry helps in ascertaining the exposure and quantifies the radiation dose using biological indicators of radiation when either physical dosimeters become unreliable or not available.

The principle of bio dosimetry is to utilize changes induced in the individual by ionizing radiation to estimate the dose and, if possible, to predict the biological consequences of the dose or the clinically relevant response [1]. There are three basic types of bio dosimetry with different and often complementary characteristics: (a) based on qualitative and quantitative changes in gene activation or chromosomal abnormalities; (b) based on quantitative changes in viability of cells and biochemical parameters of tissues and fluids; (c) based on physical changes in tissues. However, there is no single biological indicator which can fulfill all the requirements to meet challenges of dose estimation, owing to complexities of exposure scenarios [2]. Thus, among different bio dosimeters there is a need in methods that can rapidly and accurately determine individual exposure to ionizing radiation during examination a big cohort of people [3,4]. For example, such methods can be useful in identification of those who need medical assistance and guiding appropriate medical treatment in an emergency response to nuclear accidents and large-scale radiological emergencies.

In our previous studies the significant involvement of zinc ( $\mathrm{Zn})$, calcium (Ca), magnesium $(\mathrm{Mg})$, rubidium $(\mathrm{Rb})$ and some other trace elements (TEs) in the function of the prostate was found [515]. Moreover, it was demonstrated that the changes of $\mathrm{Zn}$ content and $\mathrm{Zn}$ relationships with other TE in the prostate tissue can be used as biomarkers of prostate disorders [16-39].

One of the main functions of the prostate gland is the production of prostatic fluid [40]. It contains a high concentration of $\mathrm{Zn}$ and 
elevated levels of $\mathrm{Ca}, \mathrm{Mg}$, $\mathrm{Rb}$, and some other TEs, in comparison with levels in serum and other human body fluids. The first finding of remarkably high levels of $\mathrm{Zn}$ in human expressed prostatic fluid (EPF) was reported in the early 1960s [41]. After analyzing EPF expressed from the prostates of eight apparently healthy men, aged 25 - 55 years, it was found that $\mathrm{Zn}$ concentrations varied from 300 to $730 \mathrm{mg} / \mathrm{L}$. After this finding several investigators suggested that the measurement of $\mathrm{Zn}$ levels in EPF may be useful as a marker of abnormal prostate secretory function [42-60].

It is well known that ionizing radiation (IR) could inevitably damage normal function of human body organs and tissues that usually induce such effects as lowering of the immune response, injury to the hematopoietic system, gastrointestinal system and central nervous system and also induce many other disturbances [61-63]. It is especially concerns the reproductive organs of man which functions are very sensitive to IR. There are a lot of papers and reviews focused on the disturbances in hormonal status (testosterone and gonadotrophin levels), on the causative effects in spermatogenesis (gravity of the oligospermia or azoospermia), on the testicular volumes decline and others abnormalities following total body irradiation in adults [63-67]. However, published data about the IR impact on the levels of TEs, including Zn, in EPF were not found.

The aim of the present study was to estimate the changes of $\mathrm{Zn}$ concentration in EPF during the course of external gamma therapy of patients with the bladder cancer and to assess possible application of this metal level changes for bio dosimetric purposes.

All studies were approved by the Ethical Committees of the Medical Radiological Research Centre, Obninsk. All the procedures performed in studies involving human participants were in accordance with the ethical standards of the institutional and/or national research committee and with the 1964 Helsinki declaration and its later amendments, or with comparable ethical standards.

\section{Materials and Methods}

\section{Samples}

Specimens of EPF were obtained from 38 men with apparently normal prostates $(\mathrm{N}$, mean age \pm Standard Deviation - $59 \pm 11$ years, range 41-82 years) and from 15 patients with bladder cancer (BC, mean age $51 \pm 12$ years, range 38 - 77 years) in the Urological Department of the Medical Radiological Research Centre (MRRC) using a standard rectal massage procedure. The diagnosis of each bladder condition was made by qualified urologists. The BC stage ranged from T1N0M0 to T3N0M0 and prostate glands were intact. In all cases the $\mathrm{N}$ classification of prostate were confirmed by clinical examination and by cytological and bacteriological investigations of the EPF samples. The diagnosis of $\mathrm{BC}$ had been confirmed by clinical examination and morphological results obtained during studies of biopsy and resected materials. Healthy subjects were asked to abstain from sexual intercourse for three days preceding the procedure. Patients with $\mathrm{BC}$ were treated with external (distant) gamma-ray therapy. Fractionated tumour irradiation was used with a total dose of $65 \mathrm{~Gy}$. As a rule, patients were daily treated with the dose ranged from 6 to 12 Gy in seven fractions. Direct irradiation to the bladder tumor was, in lower doses, affected the prostate. The radiation doze absorbed by prostate depends on the bladder tumor location and individual anatomical characteristics of bladder and prostate. Individual doses were calculated according to the distribution of isodose levels within the body during the simulation of external local gamma-ray irradiation to the bladder tumour. Specimens of EPF of patients with BC were obtained before the impact of IR and from 1 to 4 times during radiation therapy.

Specimens of EPF were obtained in sterile containers, which were appropriately labeled. $20 \mu \mathrm{L}$ (microliters) of fluid were taken in duplicate by micropipette from every specimen for TE analysis, while the rest of the fluid was used for cytological and bacteriological investigations. One $20 \mu \mathrm{L}$ sample of the EPF was dropped on a $11.3 \mathrm{~mm}$ diameter disk made of thin, ash-free filter paper fixed on pieces of adhesive tape and dried in a desiccator at room temperature. Then the dried sample was covered with a $4 \mu \mathrm{m}$ gage Dacron film and centrally pulled onto a Plexiglas cylindrical frame [45].

\section{Standards and certified reference material}

To determine concentration of the $\mathrm{Zn}$ by comparison with known standards, aliquots of solutions of commercial, chemically pure compounds were used for calibration [68]. The standard samples for calibration were prepared in the same way as the samples of prostate fluid. Because there were no available liquid Certified Reference Materials (CRMs), ten sub-samples of the powdered CRM IAEA H-4 (animal muscle) were analyzed to estimate the precision and accuracy of results. Every CRM sub-sample weighing about 3 mg was applied to the piece of adhesive tape serving as an adhesive fixing backing. An acrylic stencil made in the form of a thin-walled cylinder with $11.3 \mathrm{~mm}$ inner diameter was used to apply the subsample to the adhesive tape. The polished-end acrylic pestle, which is a constituent of the stencil set, was used for uniform distribution of the sub-sample upon the adhesive tape surface restricted by the stencil's inner cylindrical surface. After the sub-sample was lightly pressed onto the adhesive tape carrier, the stencil was removed. Then the sub-sample was covered with $4 \mu \mathrm{m}$ gage Dacron film. Before the sample was applied, pieces of adhesive tape and Dacron film were weighed using an analytical balance. They were reweighed after the sample had been placed inside to determine precisely the sub-sample mass [45].

\section{Standards and certified reference material}

To determine concentration of the $\mathrm{Zn}$ by comparison with known standards, aliquots of solutions of commercial, chemically pure compounds were used for calibration [68]. The standard samples for calibration were prepared in the same way as the samples of prostate fluid. Because there were no available liquid Certified Reference Materials (CRMs), ten sub-samples of the powdered CRM IAEA H-4 (animal muscle) were analyzed to estimate the precision and accuracy of results. Every CRM sub-sample weigh- 
ing about $3 \mathrm{mg}$ was applied to the piece of adhesive tape serving as an adhesive fixing backing. An acrylic stencil made in the form of a thin-walled cylinder with $11.3 \mathrm{~mm}$ inner diameter was used to apply the sub-sample to the adhesive tape. The polished-end acrylic pestle, which is a constituent of the stencil set, was used for uniform distribution of the sub-sample upon the adhesive tape surface restricted by the stencil's inner cylindrical surface. After the sub-sample was lightly pressed onto the adhesive tape carrier, the stencil was removed. Then the sub-sample was covered with $4 \mu \mathrm{m}$ gage Dacron film. Before the sample was applied, pieces of adhesive tape and Dacron film were weighed using an analytical balance. They were reweighed after the sample had been placed inside to determine precisely the sub-sample mass [45].

\section{Instrumentation and method}

The facility for the radionuclide-induced EDXRF included an annular 109Cd source with an activity of $2.56 \mathrm{GBq}, \mathrm{A}$ Si (Li) detector with an electric cooling system and a portable multi-channel analyzer based on a personal computer, comprised the detection system. Its resolution was $270 \mathrm{eV}$ at the $6.4 \mathrm{keV}$ line. The facility functioned as follows. Photons with energy $22.1 \mathrm{keV}$ from the $109 \mathrm{Cd}$ source arrived at the surface of the specimen inducing fluorescent $\mathrm{K} \alpha \mathrm{X}$-rays from the $\mathrm{Zn}$. The fluorescence reached the detector after passing through a $10 \mathrm{~mm}$ diameter collimator. Then the Xray's arrival was recorded [45]. The duration of the measurements of $\mathrm{Zn}$ concentration was $5 \mathrm{~min}$ for each sample obtained from healthy persons as well as from patients with BC before and after 1 or 2 fractions of radiation therapy. The duration of the $\mathrm{Zn}$ measurements was $60 \mathrm{~min}$ for each sample obtained from patients with BC after 3 and more fractions of radiation therapy. The intensity of the $\mathrm{K} \alpha$-line of Zn for EPF samples and standards was estimated from a calculation of the total area under the corresponding photopeak in the spectra.

\section{Computer programs and statistic}

All EPF samples for EDXRF were prepared in duplicate and mean value of $\mathrm{Zn}$ content was used in the final calculation. Using the Microsoft Office Excel programs (Windows 10), some statistical characteristics, such as arithmetic mean (M), standard deviation (SD), standard error of the mean (SEM), minimum and maximum values (Range), and median were calculated for $\mathrm{Zn}$ concentrations in the EPF of healthy persons and patients with BC. For the construction of diagram illustrating individual data set for changes of $\mathrm{Zn}$ concentrations in the EPF of patients with BC during radiation therapy, the Microsoft Office Excel software (Windows 10)was also used.

\section{Results and Discussion}

Significant agreement of the $\mathrm{Zn}$ content, analyzed by the ${ }^{109} \mathrm{Cd}$ EDXRF method, with the certified data of reference materials (Table 1) indicates an acceptable accuracy for the results obtained in the study and presented in (Figure 1 and Tables 2 and 3).
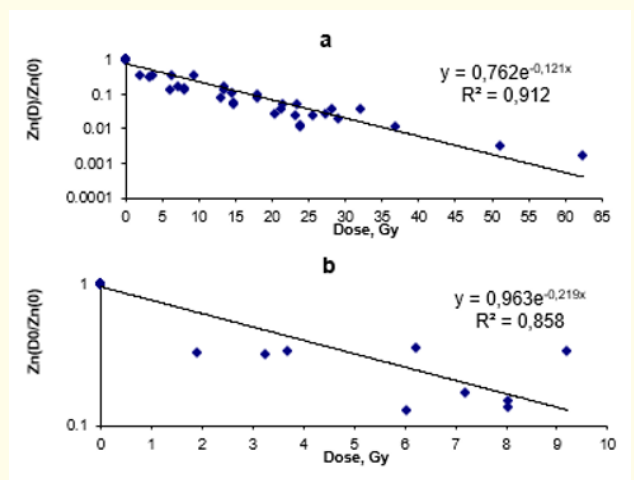

c

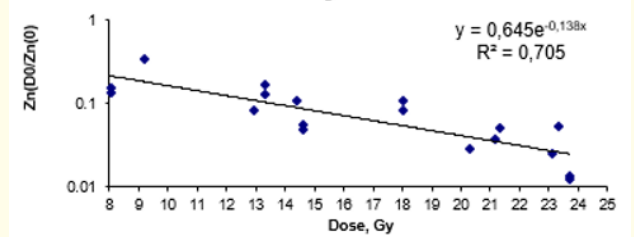

d

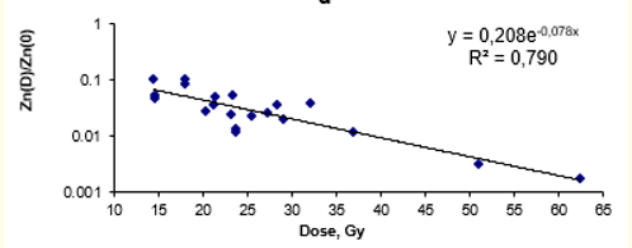

Figure 1: Individual data set for the $\mathrm{Zn}(\mathrm{D}) / \mathrm{Zn}(0)$ ratio, where $\mathrm{Zn}(0)$ and $\mathrm{Zn}(\mathrm{D})$ are concentrations of $\mathrm{Zn}$ in prostatic fluid samples obtained before (0) and during (D) fractionated radiation therapy of patients with bladder cancer: a - range of dose from 0 to $65 \mathrm{~Gy}, \mathrm{~b}$ - range of dose from 0 to $10 \mathrm{~Gy}$, c - range of dose from

10 to $20 \mathrm{~Gy}$, and d - range of dose from 20 to $65 \mathrm{~Gy}$.

\begin{tabular}{|l|c|c|c|}
\hline \multicolumn{3}{|c|}{ Certified value } & This work results \\
\hline Mean & $95 \%$ confidence interval & Type & Mean \pm SD \\
\hline 86 & $83-90$ & Certified value & $90 \pm 5$ \\
\hline
\end{tabular}

Table 1: EDXRF data Zn contents in the IAEA H-4 (animal muscle) reference material compared to certified values $(\mathrm{mg} / \mathrm{kg}$, dry mass basis).

\begin{tabular}{|c|c|c|c|c|c|}
\hline \multicolumn{4}{|c|}{ Healthy men } & \multirow{2}{*}{\multicolumn{2}{|c|}{$\begin{array}{l}\text { Patients with } \\
\text { bladder cancer }\end{array}$}} \\
\hline \multicolumn{2}{|c|}{$\begin{array}{l}\text { This work } \\
\text { results }\end{array}$} & \multicolumn{2}{|c|}{ Reference data [60] } & & \\
\hline Mean & $\pm \mathrm{SD}$ & $\begin{array}{l}\text { Median of } \\
\text { Means }\end{array}$ & $\begin{array}{l}\text { Range of } \\
\text { Means }\end{array}$ & Mean & $\pm \mathrm{SD}$ \\
\hline 598 & 207 & 580 & $490-598$ & 588 & 408 \\
\hline
\end{tabular}

Table 2: Concentrations of $\mathrm{Zn}(\mathrm{mg} / \mathrm{L})$ in the prostatic fluid of healthy men and patients with bladder cancer before radiation therapy.

Both mean value and the range of $\mathrm{Zn}$ concentration in the EPF of healthy males agree well with the reference data (Table 2). The Zn concentration in the EPF of patients with BC did not differ from that in healthy subjects (Table 2). 


\begin{tabular}{|c|c|c|c|c|c|c|c|c|c|c|c|c|c|c|}
\hline \multirow{2}{*}{ No } & \multicolumn{2}{|c|}{ Fraction 1} & \multicolumn{2}{|c|}{ Fraction 2} & \multicolumn{2}{|c|}{ Fraction 3} & \multicolumn{2}{|c|}{ Fraction 4} & \multicolumn{2}{|c|}{ Fraction 5} & \multicolumn{2}{|c|}{ Fraction 6} & \multicolumn{2}{|c|}{ Fraction 7} \\
\hline & D & Ratio & D & Ratio & D & Ratio & D & Ratio & D & Ratio & D & Ratio & D & Ratio \\
\hline 1 & - & - & 9.2 & 0.342 & - & - & 25.5 & 0.023 & - & - & - & - & - & - \\
\hline 2 & 3.3 & 0.319 & - & - & - & - & 23.3 & 0.054 & - & - & - & - & - & - \\
\hline 3 & 3.7 & 0.338 & - & - & 12.9 & 0.083 & 20.3 & 0.028 & 36.9 & 0.0122 & - & - & - & - \\
\hline 4 & 1.9 & 0.327 & - & - & 13.3 & 0.168 & - & - & 32.1 & 0.0378 & - & - & 62.3 & 0.0017 \\
\hline 5 & - & - & - & - & 13.3 & 0.129 & - & - & - & - & 51.0 & 0.0032 & - & - \\
\hline 6 & - & - & 6.2 & 0.357 & - & - & 21.4 & 0.050 & - & - & - & - & - & - \\
\hline 7 & - & - & - & - & - & - & 28.2 & 0.037 & - & - & - & - & - & - \\
\hline 8 & - & - & - & - & 18.0 & 0.104 & - & - & - & - & - & - & - & - \\
\hline 9 & - & - & - & - & 18.0 & 0.084 & - & - & - & - & - & - & - & - \\
\hline 10 & - & - & 6.0 & 0.130 & - & - & 21.2 & 0.037 & - & - & - & - & - & - \\
\hline 11 & - & - & & & - & - & 27.2 & 0.026 & - & - & - & - & - & - \\
\hline 12 & - & - & 7.2 & 0.171 & 14.4 & 0.106 & 23.1 & 0.025 & - & - & - & - & - & - \\
\hline 13 & - & - & - & - & - & - & 29.0 & 0.020 & - & - & - & - & - & - \\
\hline 14 & - & - & 8.0 & 0.135 & 14.6 & 0.049 & 23.7 & 0.012 & - & - & - & - & - & - \\
\hline 15 & - & - & 8.0 & 0.150 & 14.6 & 0.054 & 23.7 & 0.013 & - & - & - & - & - & - \\
\hline $\mathrm{M}$ & 2.9 & 0.328 & 7.5 & 0.214 & 14.9 & 0.097 & 24.2 & 0.030 & 34.5 & 0.025 & 51.0 & 0,0032 & 62.3 & 0.0017 \\
\hline SD & 0.9 & 0.009 & 1.2 & 0.105 & 2.0 & 0.039 & 2.9 & 0,014 & 3.4 & 0.018 & - & - & - & - \\
\hline
\end{tabular}

Table 3: Impact of the dose (D, Gy) on the $\mathrm{Zn}(\mathrm{D}) / \mathrm{Zn}(0)$ ratio (Ratio), where $\mathrm{Zn}(0)$ and $\mathrm{Zn}(\mathrm{D})$ are concentrations of $\mathrm{Zn}$ in prostatic fluid samples obtained before $(0)$ and during (D) fractionated radiation therapy of patients with bladder cancer. No - index of patient.

The experimental results show that during fractional radiation therapy the $\mathrm{Zn}$ concentration in the EPF of patients with BC drastically decreased and by the end of treatment (after 7th fraction) the Zn concentration in the EPF was almost three orders of magnitude lover than that before therapy (Figure 1 and Table 3). After the 1st fraction when the mean of dose to prostates of three patients was about 2.9 Gy the mean of Zn concentration in the EPF of these patients was 3 times lower than that before therapy (Table 3). After the fours fraction when the mean of dose to prostates of eleven patients was about 24 Gy their mean of $\mathrm{Zn}$ concentration in the EPF was 30 times lower than that before therapy (Table 3).

Dose-dependent decrease of $\mathrm{Zn}$ concentration in the EPF was more ideally fitted by an exponential law than by a linear, polynomial, logarithmic or power law (Figure 1a):

$\operatorname{Zn}(\mathrm{D}) / \operatorname{Zn}(0)=0.762 \cdot \mathrm{e}^{-0.121 \mathrm{D}}$

Where $\mathrm{D}$ is radiation dose to prostate in range from 0 up to 65 Gy, Zn(0) and Zn(D) are concentrations of $\mathrm{Zn}$ in EPF samples obtained before (0) and after (D) irradiation in dose D. The accuracy of approximation can be improve, if to use three range of dose: from 0 to $10 \mathrm{~Gy}$, from 10 to $20 \mathrm{~Gy}$, and from 20 to $65 \mathrm{~Gy}$ (Figures $1 \mathrm{~b}$, $1 \mathrm{c}$, and $1 \mathrm{~d}$, respectively).

The ratio Zn (D)/Zn (0) in EPF has many advantages over other biodosimetric markers under conditions of acute exposure. For example, it is more sensitive than cytogenetic indices. For comparison, after irradiation of prostate in dose 1 Gy the Zn level in EPF decreased in $30 \%$ (Figure 1b), while changes in cytogenetic indices ranged between $10 \%$ and $25 \%$ depending on the test used [69]. A dose detection threshold determined by us as the $9 \%$ reduction of
$\mathrm{Zn}$ content in EPF (over 3 total errors of $\mathrm{Zn}$ measurements) corresponded $10 \mathrm{cGy}$. Thus, concentration of $\mathrm{Zn}$ in the EPF is potentially sensitive In vivo assay for early radiation biological dosimetry in the wide range of doses from 0.1 to $65 \mathrm{~Gy}$.

In present study the portable device used for 109Cd EDXRF analysis of Zn level in EPF samples was developed by us. More powerful devices for EDXRF analysis with X-ray tubes, including "the total reflection" version (TRXRF) of the method, allow reliable determinations of $\mathrm{Zn}$ in a drop of EPF with concentration of metal up to $1 \mathrm{mg} / \mathrm{L}$ within $10 \mathrm{~min}$ [70]. EDXRF is a fully instrumental and non-destructive method because a drop of EPF is investigated without requiring any sample pretreatment or its consumption. Moreover, it is well known that among the most modern analytical technologies, EDXRF is one of the simplest, fastest, most reliable and efficient of the available techniques for TE determination [70]. There are many different kinds of EDXRF and TRXRF device on the market and technical improvements are frequently announced. Thus, it is need no more than $10 \mathrm{~min}$ for the determination of $\mathrm{Zn}$ in the EPF sample using the modern EDXRF and TRXRF device. For comparison, biodosimetry using intra- and inter-chromosomal aberrations detection in human lymphocyte takes about 3 - 4 days for radiation dose estimation [4].

Cytogenetic analysis of the peripheral blood lymphocytes is a long-established gold standard technique. It is a biomarker of IR exposure, but it requires large time and trained workers for analysis [71]. Moreover, it is the invasive method because needs in a venipuncture. The method presented here for biodosimetry overcame all these problems. It use a noninvasive and safe procedure because only requires a drop of EPF which obtained by prostate gland massage. Many urologists have successfully and easily ob- 
tained EPF this way, so it seems likely that others will be able to do likewise for most of their patients. Determination of the $\mathrm{Zn}$ concentration in the EPF sample using the modern EDXRF and TRXRF device takes 10 min. EDXRF or TRXRF analysis of Zn concentration in the EPF sample is the full instrumental method that does not require any sample treatment and high trained workers. Thus, in our opinion, the Zn level assessment in a drop of EPF, using EDXRF, is a fast, reliable, and non-invasive tool for early radiation biodosimetry that can be successfully used by physicians, who are not urologists, or by paramedics.

This study has several limitations. To clarify the usefulness and possible application of the $\mathrm{Zn}$ level assessment in EPF as bio dosimeter after radiation exposure, future studies should be directed toward receiving answers about (1) individual variations of the $\mathrm{Zn}$ level in the EPF of healthy males from day to day, (2) effect of race, nationality, diet, sexual and physical activity, climate and other factors on the $\mathrm{Zn}$ level in the EPF of healthy males, (3 changes of the $\mathrm{Zn}$ level in the EPF after total body irradiation, (4) the recovery dynamics of prostate function after total body irradiation.

\section{Conclusion}

It is a general consensus that there is yet no perfect biomarker of radiation exposure in the field of biological radiation dosimetry. The present work is a preliminary study regarding the application of $\mathrm{Zn}$ concentration in EPF as a biomarker for the assessment of prostate radiation exposure during external (distant) gamma-ray therapy of patients with bladder cancer. The study has demonstrated that $\mathrm{Zn}$ concentration in EPF is the very sensitive marker of radiation exposure. Thus, the $\mathrm{Zn}$ level assessment in a drop of EPF, using EDXRF, is a fast, reliable, and non-invasive tool for early radiation biodosimetry that can be successfully used by paramedics. The future studies need to clarify a possibility of using the $\mathrm{Zn}$ level in EPF as the radiation dosimeter for both local and total body irradiation, acute and chronic radiation exposure, and retrospective dosimetry.

\section{Bibliography}

1. Swartz HM., et al. "Overview of the principles and practice of biodosimetry". Radiation and Environmental Biophysics 53.2 (2014): 221-232.

2. Bhat NN., et al. "Biodosimetry techniques and the biological indicators of radiation exposure in humans". BARC Newsletter 365 (2018): 22-30.

3. He X., et al. "Development and validation of an ex vivo electron paramagnetic resonance fingernail biodosimetric method". Radiatation Protection Dosimetry 159.1-4 (2014): 172-181.

4. Ryan TI., et al. "Use of human lymphocyte G0 PCCs to detect intra- and inter-chromosomal aberrations for early radiation biodosimetry and retrospective assessment of radiation-induced effects". PLoS One 14.5 (2019): e0216081.
5. Zaichick V., et al. "Zinc in the human prostate gland: normal, hyperplastic and cancerous". International Urology and Nephrology 29.5 (1997): 565-574.

6. Zaichick V. "INAA and EDXRF applications in the age dynamics assessment of $\mathrm{Zn}$ content and distribution in the normal human prostate". Journal of Radioanalytical and Nuclear Chemistry 262 (2004): 229-234.

7. Zaichick S and Zaichick V. "Method and portable facility for energy-dispersive X-ray fluorescent analysis of zinc content in needle-biopsy specimens of prostate". X-Ray Spectrometry 39 (2010): 83-89.

8. Zaichick $\mathrm{S}$ and Zaichick V. "INAA application in the age dynamics assessment of $\mathrm{Br}, \mathrm{Ca}, \mathrm{Cl}, \mathrm{K}, \mathrm{Mg}, \mathrm{Mn}$, and $\mathrm{Na}$ content in the normal human prostate". Journal of Radioanalytical and Nuclear Chemistry (2011): 197-202.

9. Zaichick $\mathrm{S}$ and Zaichick V. "The effect of age on $\mathrm{Ag}, \mathrm{Co}, \mathrm{Cr}, \mathrm{Fe}$, $\mathrm{Hg}, \mathrm{Sb}, \mathrm{Sc}, \mathrm{Se}$, and Zn contents in intact human prostate investigated by neutron activation analysis". Applied Radiation and Isotopes 69 (2011): 827-833.

10. Zaichick S and Zaichick V. "The Br, Fe, Rb, Sr, and Zn contents and interrelation in intact and morphologic normal prostate tissue of adult men investigated by energy-dispersive X-ray fluorescent analysis". X-Ray Spectrometry 40.6 (2011): 464469.

11. Zaichick S and Zaichick V. "Trace elements of normal, benign hypertrophic and cancerous tissues of the human prostate gland investigated by neutron activation analysis". Applied Radiation and Isotopes 70 (2012): 81-87.

12. Zaichick V., et al. "The effect of age on 12 chemical element contents in intact prostate of adult men investigated by inductively coupled plasma atomic emission spectrometry". Biological Trace Element Research 147 (2012): 49-58.

13. Zaichick S., et al. "Mass fractions of 52 trace elements and zinc trace element content ratios in intact human prostates investigated by inductively coupled plasma mass spectrometry". Biological Trace Element Research 149. 2 (2012): 171-183.

14. Zaichick S and Zaichick V. "Relations of morphometric parameters to zinc content in paediatric and nonhyperplastic young adult prostate glands". Andrology 1.1 (2013): 139-146.

15. Zaichick $\mathrm{V}$ and Zaichick $\mathrm{S}$. "The effect of age on $\mathrm{Br}, \mathrm{Ca}, \mathrm{Cl}, \mathrm{K}, \mathrm{Mg}$, $\mathrm{Mn}$, and Na mass fraction in pediatric and young adult prostate glands investigated by neutron activation analysis". Applied Radiation and Isotopes 82 (2013): 145-151.

16. Zaichick $V$ and Zaichick $S$. "INAA application in the assessment of $\mathrm{Ag}$, $\mathrm{Co}, \mathrm{Cr}, \mathrm{Fe}, \mathrm{Hg}, \mathrm{Rb}, \mathrm{Sb}, \mathrm{Sc}$, Se, and Zn mass fraction in pediatric and young adult prostate glands". Journal of Radioanalytical and Nuclear Chemistry 298 (2013): 1559-1566.

17. Zaichick V and Zaichick S. “NAA-SLR and ICP-AES Application in the assessment of mass fraction of 19 chemical elements in pediatric and young adult prostate glands". Biological Trace Element Research 156 (2013): 357-366. 
18. Zaichick V and Zaichick S. "Use of neutron activation analysis and inductively coupled plasma mass spectrometry for the determination of trace elements in pediatric and young adult prostate". American Journal of Analytical Chemistry 4 (2013): 696-706.

19. Zaichick V and Zaichick S. "Relations of bromine, iron, rubidium, strontium, and zinc content to morphometric parameters in pediatric and nonhyperplastic young adult prostate glands". Biological Trace Element Research 157 (2014): 195-204.

20. Zaichick V and Zaichick S. "Relations of the neutron activation analysis data to morphometric parameters in pediatric and nonhyperplastic young adult prostate glands". Advances in Biomedical Science and Engineering 1.1 (2014): 26-42.

21. Zaichick V and Zaichick S. "Relations of the $\mathrm{Al}, \mathrm{B}, \mathrm{Ba}, \mathrm{Br}, \mathrm{Ca}, \mathrm{Cl}$, $\mathrm{Cu}, \mathrm{Fe}, \mathrm{K}, \mathrm{Li}, \mathrm{Mg}, \mathrm{Mn}, \mathrm{Na}, \mathrm{P}, \mathrm{S}, \mathrm{Si}, \mathrm{Sr}$, and Zn mass fractions to morphometric parameters in pediatric and nonhyperplastic young adult prostate glands". Bio Metals 27 (2014): 333-348.

22. Zaichick V and Zaichick S. "The distribution of 54 trace elements including zinc in pediatric and nonhyperplastic young adult prostate gland tissues". Journal of Clinical and Laboratory Investigation Updates 2.1 (2014): 1-15.

23. Zaichick V and Zaichick S. "Androgen-dependent chemical elements of prostate gland". Andrology and Gynecology: Current Research 2 (2014): 2.

24. Zaichick V and Zaichick S. "Differences and relationships between morphometric parameters and zinc content in nonhyperplastic and hyperplastic prostate glands". British Journal of Medicine and Medical Research 8.8 (2015): 692-706.

25. Zaichick V and Zaichick S. "Trace element levels in prostate gland as carcinoma's marker". Journal of Cancer Therapy 8 (2017): 131-145.

26. Zaichick V and Zaichick S. "Ratios of selected chemical element contents in prostatic tissue as markers of malignancy". Hematology and Medical Oncology 1.2 (2016): 1-8.

27. Zaichick V and Zaichick S. "Ratios of $\mathrm{Zn} /$ trace element contents in prostate gland as carcinoma's markers". Cancer Reports and Reviews 1.1 (2017): 1-7.

28. Zaichick V and Zaichick S. "Ratios of selenium/trace element contents in prostate gland as carcinoma's markers". Journal of Tumor Medicine and Prevention 1.2 (2017): 555-556.

29. Zaichick V and Zaichick S. "Ratios of rubidium/trace element contents in prostate gland as carcinoma's markers". Cancer Research and Clinical Oncology 1.1 (2017):13-21.

30. Zaichick V and Zaichick S. "Ratios of cadmium/trace element contents in prostate gland as carcinoma's markers". Cancer Therapy and Oncology International Journal 4.1 (2017): 555626.
31. Zaichick V and Zaichick S. "Ratios of cobalt/trace element contents in prostate gland as carcinoma's markers". The International Journal of Cancer Epidemiology and Research 1.1 (2017): 21-27.

32. Zaichick V and Zaichick S. "Ratios of calcium/trace elements as prostate cancer markers". Journal of Oncology Research and Therapy 4 (2017): J116.

33. Zaichick V and Zaichick S. "Ratios of Mg/trace element contents in prostate gland as carcinoma's markers". SAJ Cancer Science 2.1 (2017): 102.

34. Zaichick V and Zaichick S. "Age-related changes in concentration and histological distribution of 54 trace elements in nonhyperplastic prostate of adults". International Archives of Urology and Complications 2.2 (2016): 019.

35. Zaichick V and Zaichick S. "Trace element levels in prostate gland as carcinoma's markers". Journal of Cancer Therapy 8 (2017): 131-145.

36. Zaichick V and Zaichick S. "Chemical element contents in normal and benign hyperplastic prostate". Annals of Men's Health and Wellness 1.2 (2017): 1006.

37. Zaichick V. "The variation with age of 67 macro- and microelement contents in nonhyperplastic prostate glands of adult and elderly males investigated by nuclear analytical and related methods". Biological Trace Element Research 168.1 (2015): 44-60.

38. Zaichick V. "Differences between 66 chemical element contents in normal and cancerous prostate". Journal of Analytical Oncology 6.2 (2017): 37-56.

39. Zaichick V and Zaichick S. "Comparison of 66 chemical element contents in normal and benign hyperplastic prostate". Asian Journal of Urology 6.3 (2019): 275-289.

40. Zaichick V. "The prostatic urethra as a Venturi effect urinejet pump to drain prostatic fluid". Medical Hypotheses 83 (2014):65-68.

41. Mackenzie AR., et al. "Zinc content of expressed human prostate fluid". Nature (London) 193.4810 (1962): 72-73.

42. Marmar JL., et al. "Values for zinc in whole semen, fraction of split ejaculate and expressed prostatic fluid". Urology 16.5 (1980): 478-480.

43. Zaichick V., et al. "Method for diagnostics of prostate diseases". Certificate of Invention (1981).

44. Zaichick V., et al. "Zinc concentration in human prostatic fluid: normal, chronic prostatitis, adenoma, and cancer". International Urology and Nephrology 28.5 (1996): 687-694.

45. Zaichick V., et al. "Method and portable facility for measurement of trace element concentration in prostate fluid samples using radionuclide-induced energy-dispersive X-ray fluorescent analysis". Nuclear Science and Technology 27.6 (2016): 1-8. 
46. Zaichick V and Zaichick S. "Effect of age on the Br, Fe, Rb, Sr, and $\mathrm{Zn}$ concentrations in human prostatic fluid investigated by energy-dispersive X-ray fluorescent microanalysis". Micro Medicine 6.2 (2018): 94-104.

47. Zaichick V and Zaichick S. "Br, Fe, Rb, Sr, and Zn levels in the prostatic secretion of patients with chronic prostatitis". International Archives of Urology and Complications 4 (2018): 046.

48. Zaichick V and Zaichick S. "Trace element concentrations in the expressed prostatic secretion of normal and hyperplastic prostate". Journal of Urology and Nephrology Studies 1.3 (2018): 1-7.

49. Zaichick V and Zaichick S. "Trace elements of expressed prostatic secretions as a source for biomarkers of prostatic cancer". Journal of Clinical Research in Oncology 1.1 (2018): 1-7.

50. Zaichick V and Zaichick S. "Age-dependence of some trace element concentrations and their ratios in human prostatic fluid". Journal of Aging Research and Healthcare 2.4 (2019): 11-20.

51. Zaichick V. "Using prostatic fluid levels of rubidium and zinc concentration multiplication in non-Invasive and highly accurate screening for prostate cancer". Journal of Cancer Prevention and Current Research 10.6 (2019):151-158.

52. Zaichick V and Zaichick S. "Using prostatic fluid levels of zinc to bromine concentration ratio in non-invasive and highly accurate screening for prostate cancer". Journal of Hematology and Oncology Research 3.3 (2019): 21-31.

53. Zaichick V and Zaichick S. "Using prostatic fluid levels of zinc to iron concentration ratio in non-invasive and highly accurate screening for prostate cancer". SSRG International Journal of Medical Science 6.11 (2019): 24-31.

54. Zaichick V and Zaichick S. "Using prostatic fluid levels of zinc to strontium concentration ratio in non-invasive and highly accurate screening for prostate cancer". Acta Scientific Cancer Biology 4.1 (2020): 12-21.

55. Zaichick V and Zaichick S. "A systematic review of the zinc concentrations in the prostate fluid of normal and hyperplastic gland". Journal of Medical Biomedical and Applied Sciences 7.12 (2019): 303-311.

56. Zaichick V and Zaichick S. "A systematic review of the zinc concentrations in the prostate fluid of normal and cancerous gland”. Journal of Clinical Research in Oncology 2.2 (2019): 1-8.

57. Zaichick V and Zaichick S. "A systematic review of the zinc concentrations in the prostate fluid of normal and inflamed gland". International Journal of Innovative Research in Medical Science 4.12 (2019):718-724.

58. Zaichick V. "A systematic review of the main electrolytes concentrations in the prostate fluid of normal gland". Journal of Analytical and Pharmaceutical Research 8.6 (2019): 214-220.
59. Zaichick V. “Using prostatic fluid levels of some trace elements and their combinations in non-Invasive and highly accurate screening for prostate cancer". Journal of Cancer Therapy 11 (2020): 1-17.

60. Zaichick V and Zaichick S. "A systematic review of the zinc concentrations in the prostate fluid of normal gland". Acta Scientific Medical Sciences 4.1 (2020): 82-89.

61. Budagov RS., et al. "Blood trace elements as an indicator for ray exposure heaviness". Radiobiologiya 34 (1994): 49-54.

62. Zaichick V. "Medical elementology as a new scientific discipline". Journal of Radioanalytical and Nuclear Chemistry 269 (2006): 303-309.

63. Zhang J., et al. "Fractionated irradiation of right thorax induces abscopal damage on testes leading to decline in fertility". Scientific Reports 9.1 (2019): 15221.

64. Littley MD., et al. "Endocrine and reproductive dysfunction following fractionated total body irradiation in adults". Quarterly Journal of Medicine 78.287 (1991): 265-274.

65. Ogilvy-Stuart AL and Shalet SM. "Effect of radiation on the human reproductive system". Environmental Health Perspectives 101.2 (1993): 109-116.

66. Kesari KK, et al. "Radiations and male fertility". Reproductive Biology and Endocrinology 16 (2018): 118.

67. Poorvu PD., et al. "Cancer treatment-related infertility: A critical review of the evidence". JNCI Cancer Spectrum 3.1 (2019): 008.

68. Zaichick V. "Applications of synthetic reference materials in the Medical Radiological Research Centre". Fresenius Journal of Analytical Chemistry 352 (1995): 219-223.

69. Sevankaev AV and Nasonov AP. "Biological dosimetry for chromosomal aberrations of the human lymphocyte culture". Methodical recommendations. Medical Radiological research Centre, Obninsk (1979).

70. Rossmann M., et al. "Determination of key chemical elements by energy dispersive X-Ray fluorescence analysis in commercially available infant and toddler formulas consumed in UK". Nutrition and Food Technology: Open Access 2.4 (2016): 1-7.

71. Rana S., et al. "Radiation-induced biomarkers for the detection and assessment of absorbed radiation doses". Journal of Pharmacy and Bioallied Sciences 2 (2010): 189-196.

\section{Assets from publication with us}

- Prompt Acknowledgement after receiving the article

- Thorough Double blinded peer review

- Rapid Publication

- Issue of Publication Certificate

- High visibility of your Published work

Website: https://www.actascientific.com/

Submit Article: https://www.actascientific.com/submission.php

Email us: editor@actascientific.com

Contact us: +919182824667 